\title{
LENGUA Y LITERATURA EN MICHEL FOUCAULT
}

\section{Guilherme Castelo Branco}

Laboratório de Filosofía Contemporánea

Universidade Federal do Rio de Janeiro/Brasil

http://dx.doi.org/10.5209/NOMA.54771

Resumen.- Este artículo, que trabaja con los textos de Foucault, especialmente con el libro Les mots et Les Choses, de 1966, presenta las diversas percepciones entre los conceptos de lengua y literatura en la edad clásica y en la modernidad. La discrepancia entre la era de la representación y la era de la finitud y del doble, hace de la literatura, según Foucault, un trazo nuevo de la modernidad, así como el hombre estudiado por las Ciencias Humanas.

Palabras clave: lengua; literatura; modernidad; Foucault; ciencias humanas; Cervantes

Abstract.- This article, that works which the original texts of Foucault, especially with the book Les mots et Les Choses, dated of 1966, analyzes the difference between the conceptions of language and literature in the Classical Age and in the Modernity. The discrepancy between the era of representation and the era of Finitude and the Double, showed that the literature is, according to Foucault, a new suit of modernity, as well as the man that born and grow up by the news Humanities sciences.

Keyworks: language; literature, modernity; Foucault; Humanities; Cervantes

En los comienzos del libro de Michel Foucault Las palabras y las cosas hay un análisis detallado de una pintura de Velásquez. El título del capítulo, por cierto, Les suivantes, ' (en francés), con 12 páginas, da el tono de la primera parte de esta obra. Pasemos ahora a la pintura: allí, en el fondo, un espejo, que se encuentra en una habitación detrás de la sala principal, donde se puede mirar a toda la escena, en la que hay figuras de alto rango de la corte española, están Les suivantes, un perro, hasta el propio artista. En la habitación en la que están los personajes centrales del cuadro, con tanta luz como la del cuarto de atrás, están representados la infante Marguerida, doña María Agustina Sarmiento Nieto, y el bufón Nicolaso Pertusato. Añade a la escena representada, una vez más en un espejo, como si fuera una imagen de periferia y sin importancia para los menos atentos, la presencia de aquellos que ven toda la escena y todas las personas, que son nada menos que el rey Felipe IV y la reina Mariana. En la tabla están todos presentes, y todos son vistos, y, como debe ser, los nobles más importantes de la jerarquía del poder real también están viendo a los demás. Después de todo, es una pintura figurativa de la vida de la

\footnotetext{
1 Es un nombre de capitulo deliberadamente ambiguo, pues indica a los empleados (todavía importantes) de la corte, así como designa a los capítulos I a. VI del libro.
} 
corte, donde están los soberanos, personas cercanas a la pareja real, objetos, animales de su entorno, y otras cosas.

Lo que moviliza Foucault, y llama verdaderamente su atención es el juego representativo, donde todos se presentan en ese campo de visión en la que, por el juego de la perspectiva, el pintor, los personajes de la corte, la princesa, el perro y reyes, los entornos, los distintos campos de luz-, todo se presenta como tal en el campo figurativo. Nada escapa a este campo pictórico, nada se elide, incluso quien pinta. Todo está expuesto, abierto a la mirada del espectador de la pintura, que en realidad ocupa el lugar que sería el del gran espejo en el que toda la escena y todos los personajes se reflejan y en la que no falta nada. El espectador vivencia la percepción de que tiene ante sí la presencia absoluta de todos los signos representativos, ya que toma el lugar del propio espejo; así, nada escapa al poder de representación del espectador, de modo que él lo asiste como intérprete marco, por la sencilla razón de que sólo aparece como depositario del sujeto de la representación presentada en esta tela de Velásquez. Básicamente, y esto es lo que Foucault busca describir, la pintura es como un icono de una época en que el mundo es concebido como una representación pura del mundo celebrada como tal en el espíritu humano, a través del cual se hace posible representar el total de las cosas. Velásquez indica, con su arte, toda una época.

Las Niñas, para Foucault, personifica en realidad el espíritu de toda la era clásica, indicando con precisión la "experiencia desnuda del orden y de sus modos de ser ( FOUCAULT, 1966, p 13) vivida en su tiempo : la pintura, según los artistas de la Edad Clásica, entre ellos Velázquez, fue una imanación y signo de la capacidad de la representación (aunque la perspectiva haya creado su peculiar capacidad de representación no sin una dosis de ilusión y de matemáticas ). ${ }^{2}$ Sólo mucho más tarde, en el siglo XIX, se rompió con esta idea de que la pintura es el arte más ejemplar debido a su capacidad figurativa, y que apuntaba por su fuerza como expresión del lenguaje libre. En la Edad Clásica, por último, el arte, o mejor dicho, su expresión más alta y completa, que es la pintura, es testimonio del mundo figurativo, es la expresión que trae la verdad personificada en la capacidad representativa del espíritu humano, que permite establecer una configuración efectiva y real del surgimiento de los lazos entre la figuración iniciada en el entendimiento humano y el trabajo de ejecución material de la obra de arte. El clásico es, en particular, una gramática, que opera las conexiónes entre los signos que representan y el pensamiento con su fuerza, así como la singularidad, que está en su mano para lograr este tipo de articulación entre el pensamiento y el lenguaje: "una idea puede ser signo de una otra no solamente por lo

\footnotetext{
2 El libro de Jacqueline Lichtenstein pude ser de gran valor para la significación de la arte el Edad Clásica. Véase la bibliografía.
} 
que puede firmar entre ellas una ligación de representación, sino también por lo que esa representación puede representar en el interior de la idea que representa. $O$, aún, que en esencia propia, la representación es siempre perpendicular a ella misma: ella es, al mismo tiempo, indicación y aparecer; relación con un objeto y manifestación de si.".(FOUCAULT, 1966, p. 79).

Los seis capítulos que constituyen la primera parte de Las palabras y las cosas desarrollan, describen y explican la Edad Clásica, llamada por Foucault como la 'Era de la Representación'. Allí el pensamiento y los tiempos verbales, son considerados como diferentes apariencias, signos del espíritu humano, a vez considerado condición esencial para el conocimiento de la realidad en su devenir. La realidad, en este periodo, podría ser comprendida como una emanación del espíritu, al contrario del platonismo y aristotelismo que sustentan la tesis de que la realidad prima sobre el pensamiento. Las Ciencias, en la era de la representación, estudian sobre todo los signos, y perciben cosas que son puestas delante de nosotros como derivaciones de nuestro poder de establecer un mundo de acuerdo con una cierta lógica, que es aquella situada en nuestra alma. Al exponer el orden de las cosas, las ciencias, finalmente, indican y describen un mundo en la que todo se presenta como una orden era totalmente cognoscible y - además según la estructura de la naturaleza humana pensante. Así, el lenguaje en la era clásica, es una expresión del pensamiento, es a través del lenguaje que revela la estructura y la seguridad ofrecida por las ideas. El lenguaje viste y reviste el pensamiento, que es la carne primera del conocimiento: imprime, en primer lugar orden y diferencia comparativa( lógica) entre las representaciones, luego, en el mundo creado por las ciencias, sus representaciones.

El papel del cuadro de Velásquez en Les mots et les choses es el de indicar y traducir en imágenes la descripción verbal que fue hecho por Foucault sobre la Edad Clásica, adonde había igualdad perfectamente compatible entre la representación pictórica y la verbal, sólo tiene que colocar de manera clara y completa, los elementos que componen las partes que componen el todo y representarlos. Cuando Foucault describe el cuadro de Velázquez en el primer capítulo del libro, explica en una síntesis inusual todos los aspectos de toda una etapa del pensamiento occidental, de acuerdo con la noción de episteme desarrollado por el filósofo francés.

Sin embargo, en la segunda parte de Las palabras y las cosas, Foucault trae una tesis absolutamente innovadora. Para él, a finales del siglo XVIII hubo una mutación en el orden general de conocimiento en el mundo occidental, sobre todo en el cambio de la concepción del lenguaje, lo que desestabilizaría todo el pensamiento de la época clásica "en el campo del lenguaje, la palabra sufre, más o menos al mismo tiempo, una transformación similar: no deja de tener un sentido y representa 
"algo en el espíritu de aquellos que hablan o escuchan, pero este papel no es constitutivo de la palabra en su propio ser, en su arquitectura esencial, lo que permite que se lleve a cabo dentro de una oración y para asociarse con otros palabras más o menos diferentes. Si la palabra puede aparecer en un discurso en el que dice algo, no será a causa de un discurso que iba a celebrar en sí y por derecho de nacimiento, pero debido a su manera, los sonidos que constituyen los cambios que experimenta de acuerdo con las funciones gramaticales que ocupa las modificaciones que sufre finalmente - a través del tiempo, se sigue una serie de leyes estrictas que regulan de manera similar todos los otros elementos de la misma lengua-, por lo que la palabra sólo está vinculada a una representación que por principio parte de una organización gramatical por el cual el lenguaje define y asegura su coherencia. Así que la palabra para significar lo que dice, es necesario que la misma pertenezca a una totalidad gramatical que, frente a ella, en primer lugar es esencial y decisiva " (FOUCAULT, 1966, P. 293).

En el umbral del siglo XVIII hasta el siglo XIX, se percibe un desvío significativo en la estructura general del conocimiento, ya que hay un cambio en la episteme, donde el lenguaje y la lengua pasan a ser como una realidad relativamente independiente de la conciencia y de la comprensión humana. La lengua es vista como teniendo una historia suya, que puede ser objeto de análisis por los estudiosos que la entienden como una realidad material con sus marcas históricas. Autónoma, una vez que funciona como una estructura o sistema que envía sus elementos, todo el tiempo, el uno al otro, la lengua ya no es el rostro de las cosas del Cogito; nos adentramos en el viraje de la era de la representación, sin el primado de la representación.. Además, ya no si considera al lenguaje como un instrumento natural para mostrar los conocimientos obtenidos clara y sistemáticamente según la correcta aplicación de la inteligencia. El lenguaje deviene, a partir de entonces, un campo independiente de la consciencia y de la razón. No es más un signo figurativo del entendimiento, que en la edad clásica tendría el poder de, a partir de la "....más sencilla representación, desarrollar poco a poco el gran cuadro de todo lo que es representable" (FOUCAULT, 1966, p. 255).

Lejos de ser una ropa del pensamiento, el lenguaje afecta de manera nebulosa el comportamiento y la forma de ser y de vivir de todos los participantes de la vida social. Todas las personas, con sus discursos y sus diversos vocabularios, así como con su uso adecuado o inadecuado de las convenciones del lenguaje, ellos dan testimonio de la fuerza y la relativa independencia de la lengua en relación con sus usuarios. Luego, el lenguaje es una estructura o sistema que existe (y sigue siendo) una región más grande que aquél de los sujetos privados y cerrados que están marcadas por el campo semántico, pragmático y sintáctico de la lengua. Las consecuencias de este cambio en la forma 
en que percibimos el lenguaje son muchas: la lingüística, la crítica, la filología, las técnicas de interpretación, los análisis formales del lenguaje son algunos de los nuevos campos de estudio de la lengua. El lenguaje está para ser conocido, una vez que- ahora el Cogito ylol impensado están hermanados en su presencia aleatoria en el mundo.

Lo más importante, para Foucault, con la transformación del estatus de la lengua, - es sin embargo, el hecho de que este giro histórico de la episteme fue lo que hizo posible ".... la aparición de la literatura " (FOUCAULT, 1966, p . 312/313). Esta es una frase inusual, con un lugar destacado en el contexto del libro. Lo que entra en juego es la concepción foucaultiana de la literatura, su alcance, su manera, su destino. Que lo que llamamos literatura existe por mucho tiempo, que todos conocemos. Pero el significado de lo que se conoce por la palabra "literatura», para Foucault, es toda otra: se refiere, desde el siglo. XIX, al acto puro de la escritura, de acuerdo con un nuevo tipo de lenguaje que se va a manifestar y sin ninguna dependencia de las ideas y representaciones. Según Foucault, al hablar de literatura, hablamos de una novedad: "... la palabra es de fecha reciente, así como es en nuestra cultura el aislamiento de un lenguaje singular que tiene por modalidad personal la de ser "literario"(Foucault, 1966, p. 313) ${ }^{3}$. El lenguaje de la literatura que comienza a existir en el siglo XIX está abierto a un mundo infinito de signos que se suman y se acumulan en una virtual y infinita expansión del universo de significados y de creación de nuevas conexiones. Desde este punto de vista, el lenguaje siempre se manifiesta como aversión al deseo de muchos en controlarlo y seguirá enigmática en su origen; en verdad, el lenguaje comienza a tener un amplio universo vital de la creación, con fuerza irresistible. El campo propio de la creación literaria se convierte en el objeto de fascinación e inspiración para los escritores jóvenes, seducidos por ".... el ser salvaje e imperioso de las palabras"(FOUCAULT, 1966, p. 313). La literatura, Foucault nos recuerda - a partir de ahora se dirige a partir a sí misma, y se revela como el resultado de un extraño escritor con una extraña subjetividad, que hace el lenguaje "cintilar dentro del brillo de su ser"(FOUCAULT, 1966, p. 313), intentando ".... aprehender en el movimiento que la hace nacer, la esencia de toda literatura " (FOUCAULT, 1966, p. 313).

El lenguaje, una vez que opaco y denso, hace de la escritura como experimentación una aventura que promete encontrar una alteridad, deslizamiento de signos y significados, que es juego con el idioma e con las palabras. Por lo tanto, esto implica la relación del artista con todo el campo del lenguaje en su estado bruto que nos rodea y que

\footnotetext{
3 Es notable que la proposición más conocida de Foucault, en los años 1960, sea tan parecida a esta: "teniendo una cronologia corta y un recorte geográfico muy corto la cultura europea a partir del siglo XVI-podemos tener como seguro que el hombre es una invención reciente."
} 
incluso nos formó. En la época contemporánea, la cuestión acerca del ser del lenguaje se relaciona con la pregunta sobre "quién habla ? ", que permite respuestas tanto en el esfuerzo de formalización y la purificación de la lengua, como en el ejercicio de la experimentación en el lenguaje y con ella. Entre los escritores citados por Foucault como los representantes más importantes de la literatura contemporánea, según mi hipótesis, Mallarmé es aquel que resume el espíritu de Foucault acerca de la literatura. Mallarmé está preocupado por la belleza absoluta que se produce en la poesía y en toda el arte de escribir, que abre el ojo para la experiencia con el sonido puro de las palabras, por la ruptura con la sintaxis y el uso normal de la lengua. Mallarmé dice que es un poeta ' atrapado ' por el poder del lenguaje y la posibilidad de hacer idioma. Al mismo tiempo, Mallarmé tenía la percepción del poder pictórico de la palabra en el poema y el propio poema en su conjunto, un aspecto que ha sido desarrollado con el genio de Apollinaire. Foucault no se detiene con indicación de Mallarmé y, en su percepción de la literatura, apunta a otros iconos: "para la nueva forma de ser de la literatura, era necesario que se diera a conocer en obras como las de Artaud o Roussel - y en hombres como ellos" ( Foucault, 1966, p.395 ). Las obras de Artaud llamaran a la violencia de la plasticidad, la carne, la materialidad del pensamiento, lejos del cogito. Las obras de Roussel, recuerda Foucault, ponen en escena la muerte indefinidamente repetida y reducen a polvo la lógica narrativa y el discurso. La lista de escritores del filósofo francés crece aún más en el siguiente pasaje en el que Foucault se refiere a "esa región informe muda, insignificante en la cual el lenguaje se puede liberar. Es allí, en este espacio, al fin puesto en descubierto que la literatura, por primera vez con el surrealismo (pero todavía en una forma disfrazada), y después, de manera cada vez más y más pura forma, con Kafka, con Bataille, con Blanchot, se tomó como experiencia" (FOUCAULT , 1966, p. 395). Esta experiencia, no debemos olvidarnos, hace hincapié en la dimensión de la muerte, en la repetición y en la finitud humana, aunque lo hace través del salfo a un umbral de expresión diferente. Los escritores y los poetas son los constructores o ensabladores de nuevas conexiones en el lenguaje, y por esta razón los creadores de nuevos estilos, tendencias y escuelas literarias .

Foucault señala, en Las palabras y las cosas, que la literatura y la gramática, aunque caras gemelas de la misma moneda, caminan en direcciones opuestas. De hecho, " la literatura es la contestación de la filología (que es, sin embargo, una figura con dos caras) : desplaza el lenguaje de la gramática hacia el poder a hablar despojado, y entonces ella se encuentra el ser salvaje e imperioso de las palabras " ( FOUCAULT , 1966, p . 313). La literatura pide estar en relación con el ser puro del lenguaje, siempre viene de una experimentación renovable y abierta realizada por escritores lanzados a la lengua. La literatura revela 
un sujeto hablante, fragmentado y no completo, que desea experimentar el contacto directo, sin fin, con el inagotable poder de la lengua; por cierto, el resultado es siempre un admirable más allá en relación al uso común y vulgar del lenguaje. La creación literaria no es un hecho trivial, ella no apunta a un lugar de apaciguamiento; en verdad, ella se da a conocer después de alguna forma de exposición al peligro inherente al acto de la creación. Al final, la literatura no está de acuerdo con el mero hecho de la existencia, con la creencia naif de que el idioma fue creado sobre todo para expresar ideas y profundizarlas en discursos bien fundados. La creación literaria no proviene de la universalidad de nuestra condición de seres de pensamiento y razón; por el contrario, la creación se desprende de la experimentación realizada por unos pocos que se atreven a lanzarse al interminable espesor de la lengua y de la lenguaje, y esta actitud es, en la práctica, sobre todo, una afirmación de la infinita inventiva del texto y su inagotable potencial significativo. La literatura, por lo tanto, no es transgresora, ni mucho menos excesiva; es, sin duda movimiento hasta el insólito, que tiende a experimentar nuevas plazas, lejos del uso cotidiano de las facultades y el uso banal del buen juicio. Por esta razón, no son los temas o los sujetos lo que marca la pauta y caracteriza a la literatura contemporánea. La clave es el acto de auto- exposición al mundo del lenguaje, no al nuestro mundo cotidiano, tal vez incluso hostil al sujeto de esta experimentación ante los signos del lenguaje, considerado radical en su presencia delante el lenguaje.

La distancia entre la Edad Clásica (sec. XVII y XVIII) y la Edad Moderna o Modernidad(desde el siglo XIX) es que la primera sólo ve lal lenguaje como una capacidad de hacer un discurso de la certidumbre y de verdad, mientras que la segunda considera el lenguaje como una estructuración para una pluralidad de campos, y entre ellos la literatura tiene lugar "... formando una especie de contra- discurso" (FOUCAULT, 1966, p. 59) . Mientras que en la edad clásica, debido a la primacía de la representación, las palabras y las cosas están separadas, con el fin de priorizar el significado, en la era moderna, con la literatura, el mundo y la superposición de idiomas, "el lenguaje ahora se vaya a crecer sin ningún punto de partida, sin fin, ni promesa " (Foucault, 1966, P. 59).

Curiosamente, el filósofo francés atribuye el nacimiento de la literatura, en Las palabras y las cosas, en un período mucho antes del siglo XIX, al escritor Miguel de Cervantes, autor de una obra inusual, Don Quijote de la Mancha. ${ }^{4}$ Don Quijote, antes de un carácter extraño, es un personaje que está tratando de llegar a ser noble buscando encontrar en el mundo que, de hecho, él lee libros, publicaciones, periódicos, historias . El mundo, para Don Quijote, tiene que ser descifrado, es decir, "Don

\footnotetext{
4 En el caso, Foucault rompe con su idea de episteme, así como con su idea de autoria; en verdad, Foucault hace a Cervantes un gran homenaje.
} 
Quijote lee el mundo para demostrar los libros " (FOUCAULT, 1966, p . 61). El Caballero de la Triste Figura se convierte en personaje de la "...primera de las obras modernas" ( FOUCAULT, 1966, p . 62). Cuando," en la segunda parte del libro, Don Quijote encuentra personajes que leerán la primera parte del texto y lo reconocen, a él mismo, como hombre real y como verdadero héroe del libro. El texto de Cervantes se despliega sobre sí mismo y cae en el mismo espesor, y se convierte para sí el objeto de su propio relato "(Foucault, 1966, p . 62). Cervantes fue así el primero en presentar en un libro todo el poder de proliferación de la palabra; el escritor español, así, escribe una obra inquietante,- y , por ello, digna de ser llamada como literatura.

La literatura, por lo tanto, es el resultado de una apuesta deliberada de una persona que trata de experimentar las posibilidades de producción de sentido que viene de una aventura de inmersión en el campo infinito y del lenguaje. El lenguaje, en este caso, es un campo autónomo e independiente, fuente de fascinación y, - por qué no? - de temor. Escritura y el riesgo son compañeros y gemelos en el acto de la creación con la palabra 5 .

\section{BIBLIOGRAFIA:}

CASTELO BRANCO, G. Filosofia e biopolítica. BH: Autêntica, 1995.

Estética da existência, resistências ao poder in Exagium $n^{\circ} 1$. Ouro Preto, 2008.(revista eletrônica)

FOUCAULT, M. - Les mots et les choses. Paris: Gallimard, 1966

Dits et écrits. Paris: Gallimard, 1994. 4 vols.

LICHTENSTEIN, J. A cor eloqüente. São Paulo: Siciliano, 1994.

MACHADO, R. Foucault, a filosofia, a literatura. Rio de Janeiro: Vozes, 2000.

\footnotetext{
5 Revisión: Fernando Más - Universidad Nacional de Córdoba - Argentina
} 